\title{
Tipificação do Comportamento dos Investidores no Mercado de Ações Brasileiro
}

\author{
José Carlos de Souza Santos ${ }^{1}$
}

\begin{abstract}
Resumo
O presente trabalho investiga o comportamento de diversos tipos de investidores no âmbito de suas atividades de compra e venda de ativos no mercado de ações brasileiro. Para tanto, observa-se, de forma agregada, como o volume de compra e venda se relaciona com o retorno passado e o retorno futuro do mercado. Destacam-se os resultados para os investidores do grupo pessoa física e investidores estrangeiros. Para o grupo pessoa física, observam-se sinais de comportamento orientado por Efeito Disposição, dado que se encontra evidência de que o grupo de investidores tende a elevar suas vendas após altas elevadas do mercado, mas o mesmo não ocorre com a mesma intensidade após quedas passadas. Para investidores estrangeiros, nota-se que o mesmo é o único a indicar correlação positiva e significante com retornos passados e também futuros. O resultado indica que o comportamento do grupo de investidores é guiado por estratégias de Momentum e que existem sinais de maior habilidade no processamento das informações, tendo em vista que suas carteiras apresentam melhor desempenho.
\end{abstract}

\section{Palavras-Chave}

Anomalias de mercado. Comportamento de investidor. Decisões de investimento. Momentum. Efeito Disposição.

\begin{abstract}
This paper investigates the behavior of groups of investors regarding their asset trading activities in the Brazilian stock market. It analyzes how the buying and selling volume is related to past and future market returns. The results stand out for individual and foreign investors. Individual investors seem to be affected by the Disposition Effect - as they increase their sales after large positive market returns, but do not do so after large negative market returns. Foreign investors, on the other hand, are the only group that demonstrates positive and significant correlation with past as well as future market returns. This result indicates that foreign investors are guided

$\bar{V}$ Este artigo pôde ser escrito graças ao apoio do Departamento de Economia da FEA/USP, da Fipe Fundação de Instituto de Pesquisas Econômicas, e da B3-Brasil, Bolsa e Balcão. Agradeço o excelente trabalho do economista Elias Cavalcante Filho, que me ajudou em todas as etapas do estudo. A ele deixo registrada a minha gratidão. Agradeço, também, aos comentários de um parecerista anônimo. Erros e omissões são devidos exclusivamente ao autor.

1 Professor - Faculdade de Economia, Administração e Contabilidade - Universidade de São Paulo Endereço: Av. Prof. Luciano Gualberto, 908 - Butantã - São Paulo/SP - CEP 05508-010. E-mail: jcdssan@usp.br - ORCiD: http://orcid.org/0000-0002-5680-0264 Recebido: 31/10/2017. Aceite: 22/05/2019.
\end{abstract}

(c) (i) (\$) Esta obra está licenciada com uma Licença Creative Commons Atribuição-Não Comercial 4.0 Internacional. 
by Momentum strategies and have greater ability to process information, considering that their portfolios show a better performance.

\section{Keywords}

Market anomalies. Investor behavior. Investment decisions. Momentum. Disposition Effect.

\section{JEL Classification}

G11. G14.

\section{Introdução}

No trabalho se analisa o viés de comportamento dos investidores em relação às suas movimentações de compra e venda de ações no mercado brasileiro. Para tanto, observa-se, de forma agregada, como o fluxo líquido de investimento, definido como a diferença entre o volume de negociações de compra e venda em relação ao volume total negociado, relaciona-se com retornos passados e futuros do mercado, para os grupos de investidores pessoa física (PF), investidor estrangeiro (IE), investidor institucional (IN), instituições financeiras (IF) e empresas não financeiras (EP).

Os dados indicam que o grupo pessoa física demonstra, no curto prazo, sinais de comportamento condizente com Efeito Disposição, isto é, tendência a liquidar rapidamente suas posições após altas elevadas do mercado, ao mesmo tempo que tende a manter sua posição após quedas no mercado. Por outro lado, nos horizontes de longo prazo essa relação é positiva, o que indica que o grupo forma suas expectativas com base em horizontes mais longos. ${ }^{1}$

Por sua vez, o grupo investidor estrangeiro apresenta fluxo de investimento positivamente relacionado com retorno passado do mercado, o que aponta que investidores desse grupo tendem a seguir estratégias de investimentos ligadas a anomalia de Momentum. Também é encontrada correlação positiva com retornos futuros, o que sinaliza o potencial do grupo em antecipar movimentos do mercado. A análise mais detalhada desse comportamento indica que a relação do fluxo de investimento com retornos futuros é aderente com a hipótese do investidor estrangeiro ter capacidade de antecipar as quedas do mercado.

1 Devido à frequência dos dados e o tamanho da janela de tempo observada, define-se no trabalho como curto, médio e longo prazos respectivamente os seguintes horizontes: cinco, 21, e 63 dias úteis. 
No caso dos investidores do tipo instituições financeiras, não é constatada significância relevante para qualquer variável, evidenciando que esse grupo, em média, não é influenciado pelos retornos passados do mercado. Os grupos empresa e investidor institucional apresentam relação negativa com retornos passados, porém o comportamento não é assimétrico em relação a retornos positivos, o que não é aderente a hipótese que os investidores desse grupo sofrem também do efeito disposição.

Os resultados encontrados são aderentes com comportamentos já documentados na literatura, tais como indícios da aplicação de estratégias de Momentum por gestores de fundos dos Estados Unidos (Grinblatt, Titman e Wermers 1995) e evidências que fluxos de investimentos estrangeiro para diversos países seguem estratégias de Momentum (Grinblatt e Keloharju 2000; Froot, O'connell e Seasholes 2001; e Kamesaka, Nofsinger e Kawakita 2003)

Também é aderente com a literatura que documenta a existência de Efeito Disposição com maior intensidade em investidores menos sofisticados, tanto no âmbito internacional (Edelen, Marcus e Tehranian 2010; Guercio e Tkac 2002; Kamesaka, Nofsinger e Kawakita 2003; Lakonishok, Josef, Shleifer e Vishny 1992; O'Connell e Teo 2009; Odean 1998) como também especificamente para o mercado brasileiro (Costa Jr, Goulart, Cupertino, Macedo, et al. 2013; Karsten 2005).

O trabalho contribui com a literatura que se propõe a analisar a heterogeneidade no padrão de investimentos dos agentes de mercado. Diferencia-se dos anteriores por apresentar análise de todos os grupos de investidores no Brasil, para os quais são disponíveis dados segregados. Ademais, o trabalho analisa os efeitos sobre a relação do fluxo de investimento com retornos passados e a assimetria nessa relação, de modo a avaliar o padrão de reação dos investidores. Além disso, documenta o padrão de relação dos fluxos de investimentos com retornos futuros, com objetivo de identificar os grupos com maior capacidade de previsão de retorno futuros. 


\section{Revisão Bibliográfica}

A teoria clássica de finanças sustenta a tese de que os investidores podem ser representados por uma função de utilidade esperada padrão de Von Neumann-Morgenstern, que oportunidades de lucro no mercado são não correlacionadas entre si e que o desempenho de mercado passado não apresenta relação com atividades de negociação futuras (Coval e Shumway 2005).

Todavia, não são raros exemplos nos quais os dados de mercado não amparam tais previsões e se observa que o desempenho passado dos investimentos tem efeitos sobre a tomada de decisão dos investidores. Uma prova disso é a constatação do feedback positivo (negativo), ou seja, a correlação positiva (negativa), entre fluxo de investimento e retornos passados observados (Grinblatt, Titman e Wermers 1995).

A descrição de diversas condutas e estratégias de investimento que fundamentam a reação dos investidores em relação ao desempenho passado de seus investimentos pode ser encontrada em literaturas mais contemporâneas. Dentre elas, destacam-se as estratégias de Momentum, Efeito Disposição, Opinião Contrária (Sobre Reação) e Stop-Loss.

Momentum é o nome atribuído ao fenômeno de mercado pioneiramente documentado por Jegadeesh e Titman (1993), em que o desempenho passado de curto prazo de um ativo tende a se manter nos períodos seguintes. A utilização de uma estratégia de Momentum ocorre quando o investidor gerencia seus ativos motivado pelo padrão dessa anomalia, esperando, portanto, que os ativos com bom desempenho permaneçam ganhando enquanto que aqueles com desempenho ruim continuem perdendo. Presume-se, diante disso, que as escolhas de investidores que seguem estratégias de Momentum estejam altamente relacionadas ao desempenho passado dos ativos, ou seja, que apresentem feedback positivo.

Os trabalhos de Griffin, Harris e Topaloglu (2003) e Badrinath e Wahal (2002) argumentam que investidores institucionais estão mais propensos a comprar ativos cujo desempenho passado tenha sido positivo. Indícios da aplicação de estratégias de Momentum por gestores de fundos dos Estados Unidos são relatados em Grinblatt, Titman e Wermers (1995). Froot, O'connell e Seasholes (2001) analisam fluxo de investimento de 44 mercados e identifica que os fluxos de investimentos estrangeiros para diversos 
desses mercados tendem a seguir estratégias de Momentum. O mesmo efeito é confirmado em Grinblatt e Keloharju (2000) no mercado finlandês e em Kamesaka, Nofsinger e Kawakita (2003) no mercado japonês.

Na América Latina também é estudado o efeito de Momentum no mercado acionário, como em Abinzano, Muga e Santamaria, (2010) e Muga e Santamaria (2007), nos quais são documentadas evidências da anomalia na Argentina, Brasil, Chile e México.

Deve-se ressaltar, entretanto, que a hipótese de que investidores adotam estratégias de Momentum justifica a correlação do comportamento com retorno passado, mas não diferencia efeitos de retornos positivos e negativos; logo, não esclarece qualquer assimetria nas relações, descritas no Efeito Disposição.

Por Efeito Disposição compreende-se a propensão dos investidores em realizar rapidamente posições vencedoras e em manter por mais tempo posições perdedoras. Este fenômeno comportamental é descrito pela primeira vez em Shefrin e Statman (1985) e fundamenta-se na teoria do prospecto de Kahneman e Tversky (1979). Assim, espera-se que os investidores não estejam dispostos a reconhecer e reagir às perdas de suas posições na mesma intensidade com a qual reconhecem e reagem aos ganhos. Contrariamente ao provocado pela estratégia de Momentum, o Efeito Disposição produz relação negativa entre retornos passados e movimentos de compra.

Não é difícil encontrar na literatura internacional estudos que apontem para maior predisposição de investidores individuais, pessoas físicas ou de varejo a sofrer com o Efeito Disposição em relação à intensidade desse mesmo efeito para os investidores institucionais (Edelen, Marcus e Tehranian 2010; Guercio e Tkac 2002; Kamesaka, Nofsinger e Kawakita 2003; Lakonishok, Shleifer e Vishny 1992; O'Connell e Teo 2009; Odean 1998). Semelhante comportamento é documentado em Karsten (2005) para o mercado brasileiro. Na mesma linha, Costa Jr et al. (2008 e 2013) elaboram experimentos para mercado brasileiro e documentam evidências de correlação do efeitos disposição com gênero, sofisticação e experiência do investidor, e Lucchesi, Yoshinaga e Castro Jr (2015) encontram evidências do efeito para gestores de fundos brasileiros. 
Os comportamentos relacionados com desempenhos passados podem também ser atrelados a mecanismos de Stop-Loss. Comumente utilizados para limitar perdas, os mecanismos de Stop-Loss desfazem as posições de investimentos quando estes acumulam um nível máximo tolerável de perda. Em um cenário em que ocorre o uso frequente de tais mecanismos, espera-se a presença de forte relação entre a atividade de negociação e grandes perdas passadas, posto que determinados níveis de perda acionam os mecanismos de Stop-Loss e realizam as posições dos investidores nos ativos perdedores. De acordo com Osler (2003), é comum que os valores de gatilho, por exemplo queda de $10 \%$ no preço, estejam situados muito próximos uns aos outros, fazendo com que os acionamentos ocorram conjuntamente.

Em contraposição à estratégia de Momentum, um outro tipo de estratégia desperta o interesse na literatura econômica: Opinião Contrária, Reversão à Média ou, também, Sobre-Reação. Fama e French (1988), Poterba e Summers (1988) e Cutler, Poterba, e Summers (1991) mostram que o retorno das ações é negativamente autocorrelacionado e que, dessa forma, o preço das ações possui tendência a retornar para sua trajetória de longo prazo. O resultado desse processo de Reversão à Média que ocorre com o preço das ações é que uma estratégia de Opinião Contrária poderia gerar excessos de retorno. De Bondt e Thaler (1985) e Chan (1988), por exemplo, montam uma carteira composta de posições compradas das ações com o pior desempenho durante certo período e de posições vendidas com as ações de melhor desempenho para o mesmo período. Essa carteira, assim montada, mostra um processo de Sobre Reação, gerando excessos de retorno.

Diante do exposto, podemos considerar duas estratégias básicas de atuação no mercado que indicam o momento de abrir e de liquidar posições:

- Momentum: revela que as posições que estão apresentando bom (mau) desempenho devem continuar dessa forma no futuro.

- Opinião Contrária (Reversão à Média ou Sobre Reação): indica que as posições que estão apresentando bom (mau) desempenho devem reverter a tendência e passar a apresentar mau (desempenho).

Da mesma forma, temos duas estratégias que servem exclusivamente para a liquidação de posições, não indicando quando ou como uma posição deve 
ser aberta, mas tão somente a forma como se dá o encerramento de uma posição previamente montada:

- Efeito Disposição: uma assimetria de comportamento que indica que o investidor liquida com mais facilidade as posições com lucro do que aquelas com prejuízo.

- Stop-Loss: indica o encerramento de posições em função de movimentos contrários extremos de mercado

Levando-se em conta que um dos objetivos do presente estudo é buscar a detecção de padrões de reação dos diferentes grupos de investidores com relação ao comportamento passado do mercado podemos entender, com relação às estratégias básicas acima listadas que:

- Os investidores que usam a estratégia de Momentum devem aumentar as compras líquidas quando o indicador de mercado apresenta alta e reduzir as compras líquidas quando o mesmo indicador mostra desempenho ruim.

- Já os investidores que adotam estratégias de Opinião Contrária possuem uma visão radicalmente oposta. Eles aceleram as compras líquidas quando o indicador de mercado cai e reduzem as compras quando o indicador de mercado sobe.

Com relação às estratégias de liquidação de posições: Efeito Disposição e Stop Loss, no âmbito desse estudo deve-se observar que:

- Os investidores que adotam o Efeito Disposição devem mostrar uma redução nas compras líquidas quando o indicador de mercado sobe e pouca ou nenhuma modificação nas compras líquidas quando o indicador de mercado cai.

- Por sua vez, aqueles investidores que usam estratégias de Stop-Loss para liquidar suas posições devem mostrar uma redução nas posições compradas para quedas acentuadas no indicador de mercado. 


\section{Dados}

Nesta seção são descritos os dados utilizados no trabalho. Inicialmente, é apresentada a variável volume financeiro de compra e venda para os diversos tipos de investidores; posteriormente é discutida a construção da variável dependente e, por fim, são expostas as variáveis independentes utilizadas.

\subsection{Volume Financeiro de Compra e Vendas dos Investidores}

A origem da variável dependente do presente estudo é o histórico do volume financeiro de compra e de venda, em milhares de reais, para todos os tipos de investidores reportados pela Bovespa. A base de dados, disponibilizada pela $B M \& F B o v e s p a$, está estruturada em frequência diária e compreende o período entre 03/01/2005 e 31/08/2015. As informações são classificadas para os seguintes grupos de investidores:

- Pessoa física (PF): investidores individuais, atuantes diretamente por meio de corretoras ou indiretamente através de clubes de investimentos.

- Institucional (IN): instituições administradoras de recursos de terceiros - fundos de investimentos, fundos de pensão, fundos multimercado, entre outros.

- Investidor estrangeiro (IE): investidores institucionais domiciliados no exterior. São usualmente instituições altamente capitalizadas e com histórico extenso de aplicações em outros mercados. Geralmente constituídos por fundos mútuos estrangeiros, hedge funds e bancos de investimento estrangeiros.

- Empresas (EP): empresas não financeiras que investem no mercado de ações. Como não é típico o investimento em ações por empresas não financeiras, entende-se que este tipo de investidor é composto por: (i) empresas de capital aberto que eventualmente operam suas próprias ações em mercado; (ii) empresas de participações e (iii) empresas de investidores profissionais, de especuladores ou de profissionais de mercado. 
- Instituições financeiras (IF): composto por sociedades financeiras e instituições de crédito (bancos comerciais, bancos de investimentos, entre outros), corretoras de valores, distribuidoras, etc.

- Outros (OU): todos os demais investidores não relacionados acima.

A partir do arranjo dos dados, é possível conhecer o valor comprado e vendido de cada um dos grupos de investidores para cada dia de negociação da amostra. Na Tabela 1 estão exibidas as médias e desvios padrão dos volumes transacionados por cada tipo de investidor, bem como o percentual desses volumes em relação ao total negociado em cada dia da amostra.

A partir das informações da tabela, pode-se inferir que, juntos, os investidores PF, IE e IN representam mais de 90\% do montante negociado, tanto para as operações de compra como para as de venda. Em termos de relevância no mercado, o investidor do tipo IF ocupa o quarto lugar com aproximadamente $8 \%$ do volume negociado, seguido por EP com quase $2 \%$ e OU $\operatorname{com} 0,1 \%$.

Tabela 1 - Média e percentual de participação por tipo de investidor

\begin{tabular}{|c|c|c|c|c|c|}
\hline \multirow[b]{2}{*}{ Variável } & \multirow[b]{2}{*}{ Investidor } & \multicolumn{2}{|c|}{ Milhares R\$ } & \multicolumn{2}{|c|}{ Percentual } \\
\hline & & Média & Desvio Padrão & Média & Desvio Padrão \\
\hline \multirow{6}{*}{ Compra } & $\mathrm{PF}$ & 1.147 .856 & 491.809 & $22,57 \%$ & $6,66 \%$ \\
\hline & $\mathbb{I N}$ & 1.651 .671 & 1.018 .574 & $29,19 \%$ & $5,08 \%$ \\
\hline & IE & 2.187 .068 & 1.417 .051 & $38,27 \%$ & $8,08 \%$ \\
\hline & EP & 107.929 & 318.136 & $1,95 \%$ & $3,38 \%$ \\
\hline & IF & 432.219 & 444.469 & $7,92 \%$ & $3,47 \%$ \\
\hline & OU & 5.082 & 15.793 & $0,10 \%$ & $0,28 \%$ \\
\hline \multirow{6}{*}{ Venda } & $\mathrm{PF}$ & 1.167 .683 & 521.508 & $22,83 \%$ & $6,67 \%$ \\
\hline & $\mathbb{I N}$ & 1.682 .229 & 1.017 .010 & $29,85 \%$ & $4,65 \%$ \\
\hline & IE & 2.166 .099 & 1.411 .576 & $37,80 \%$ & $8,53 \%$ \\
\hline & EP & 83.531 & 125.301 & $1,56 \%$ & $1,49 \%$ \\
\hline & IF & 428.335 & 416.773 & $7,85 \%$ & $3,07 \%$ \\
\hline & OU & 3.949 & 34.645 & $0,10 \%$ & $1,03 \%$ \\
\hline
\end{tabular}

Nota: A tabela indica valores das médias e desvios padrão de compra e venda para cada tipo de investidor, bem como a média e desvio padrão do percentual de participação na compra ou venda percebida em relação a todo o mercado. A frequência dos dados é diária com 2.629 observações. O desvio padrão é calculado utilizando-se a técnica de Kernel Parzen para considerar o efeito da autocorrelação. 
Vale salientar que, a partir da observação do histórico de dados, a participação de investidores do tipo outros (OU) mostrou-se pouco representativa. Ademais, pouco se sabe sobre o perfil dos investidores que compõe esse grupo. Por tais razões desprezou-se esse grupo de investidores nas demais investigações realizadas.

\subsection{Variável Dependente}

Com base no arcabouço metodológico de Kamesaka, Nofsinger e Kawakita (2003), não é utilizado o volume da compra ou da venda de forma isolada, mas uma variável capaz de captar a diferença entre a informação de venda e compra, bem como todo o volume negociado. Assim, a variável dependente escolhida para a análise, nomeada de fluxo líquido de investimento (FLI), é definida da seguinte maneira:

$$
F L I_{i, t}=\frac{C_{i, t}-V_{i, t}}{C_{i, t}+V_{i, t}}
$$

em que $i \in\{P F, I N, I E, I F, E P\}$ representa o tipo de investidor; $t$ equivale ao dia da negociação; $C_{i, t}$ e $V_{i, t}$ correspondem, respectivamente, ao saldo de compra e de venda do tipo do investidor $i$ no $t$ dia .

Pretende-se, com tal abordagem, investigar se os grupos de investidores apresentam, para cada dia da amostra, um volume de compra superior ou inferior ao volume de venda realizado, considerando sempre o montante transacionado pelo investidor em um mesmo dia. A Tabela 2 apresenta as cinco séries diárias de dados resultantes, uma para cada tipo de investidor.

\subsection{Variáveis Independentes}

Como variável independente é adotado o retorno de mercado. ${ }^{2}$ Com o mesmo, para cada dia útil $t$, são construídas as seguintes variáveis:

2 O histórico de retorno de mercado foi obtido junto ao site do NEFIN (Núcleo de pesquisas em Economia Financeira da Universidade de São Paulo) e consiste em uma média value weighted dos retornos de ativos elegíveis por critério de liquidez. 
- $R_{(-63 ;-22)}$ : retorno médio observado entre os últimos 63 e 22 dias úteis;

- $R_{(-21 ;-6)}$ : retorno médio observado entre os últimos 21 e 6 dias úteis;

- $R_{(-5 ;-1)}$ : retorno médio observado entre os últimos 5 e 1 dias úteis;

- $R_{(0)}$ : retorno contemporâneo;

- $R_{(+1 ;+5)}$ : retorno médio observado entre os próximos 1 e 5 dias úteis;

- $R_{(+6 ;+21)}$ : retorno médio observado entre os próximos 6 e 21 dias úteis;

- $R_{(+22 ;+63)}$ : retorno médio observado entre os próximos 22 e 63 dias úteis;

Ademais, e seguindo proposição similar à de Lee, Shen e Yen (2010) e Lee, Yen e Chan (2013), pratica-se um ajuste adicional na variável retorno de mercado com a finalidade de captar uma eventual assimetria no efeito desta variável. Com tal alteração é possível investigar, por exemplo, se aumentos nos preços das ações exerceriam sobre o comportamento de investidores o mesmo impacto que as quedas nos preços.

A composição desse ajuste exige dividir as variáveis retorno médio passado de mercado e retorno médio futuro de mercado em outras cinco novas variáveis, de acordo com o tipo de movimento de preços observado, a saber: Alta Elevada (AE), Alta Moderada (AM), Neutro (N), Queda Moderada (QM), Queda Elevada (QE). Cada uma dessas variáveis assume o valor do retorno de mercado, quando este apresenta valores dentro de um determinado intervalo, e valor zero, caso contrário.

A Figura 1 exibe os intervalos de corte que definem essas variáveis. A variável retorno de mercado é dividida em seus percentis de valores positivos e negativos. Os $10 \%$ dos valores positivos e os $10 \%$ dos valores negativos mais próximos a zero são definidos para a categoria Neutra N. Os intervalos subsequentes, que assumem os demais $45 \%$ dos valores negativos e positivos, são definidos em Queda Moderada QM e Alta Moderada AM respectivamente. Por fim, os valores extremos positivos são delimitados para Alta Elevada AE e os negativos, para Queda Elevada QE. 


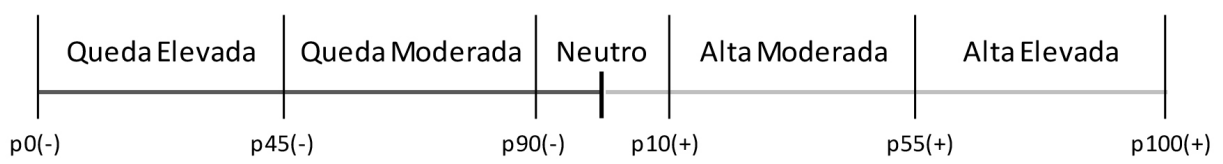

Figura 1 - Pontos de corte para variável retorno de mercado

Nota: a figura apresenta os pontos de corte aplicados para variável retorno de mercado. "pX(+)" denota percentil X do intervalo de valores positivos e "pX(-)" percentil X do intervalo de valores negativos. Cada nova variável $\mathrm{N}, \mathrm{QM}, \mathrm{AM}, \mathrm{QE}$ ou $\mathrm{AE}$ assume os valores do retorno de mercado quando esse apresenta valores dentro de um dos intervalos da figura e zero, caso contrário.

Percebe-se, assim, que além das variáveis $R_{(t 1 ; t 2)}$ construídas de acordo com o descrito anteriormente, são calculadas as seguintes variáveis de retorno:

- $R_{\left(t_{1}, t_{2}\right)}^{A E}$ : equivalente ao $R_{(t 1 ; t 2)}$, mas com valores não nulos apenas para valores positivos mais elevados;

- $R_{\left(t_{1}, t_{2}\right)}^{A M}$ : equivalente para $R_{(t 1 ; t 2)}$, mas com valores não nulos apenas para valores positivos intermediários;

- $R_{\left(t_{1}, t_{2}\right)}^{N}$ : equivalente para $R_{(t 1 ; t 2)}$, mas com valores não nulos apenas para os valores intermediários;

- $\quad R_{\left(t_{1}, t_{2}\right)}^{Q M}$ : equivalente para $R_{(t 1 ; t 2)}$, mas com valores não nulos apenas para valores negativos intermediários;

- $R_{\left(t_{1}, t_{2}\right)}^{Q E}$ : equivalente para $R_{(t 1 ; t 2)}$, mas com valores não nulos apenas para valores negativos mais baixos;

As variáveis QE e QM, por concepção, apresentam sempre sinais negativos, o que poderia atrapalhar sua compreensão, já que referir-se a "maiores perdas" equivaleria afirmar menores valores (mais negativos). Portanto, para simplificar o entendimento dessa variável, inverte-se o seu sinal.

A Tabela 2 expõe as médias e desvios padrão de todas as variáveis de interesse, estimadas a partir dos cálculos segundo as definições e procedimento supra descritos. Na coluna Abreviação encontra-se o nome que cada uma das variáveis recebe nas equações e tabelas de resultados ao longo do trabalho. 
Tabela 2 - Variáveis dependente e independentes com janelas de 5 dias

\begin{tabular}{|c|c|c|c|c|}
\hline & ariável & Abreviação & Média & Desvio padrão \\
\hline \multirow{6}{*}{$\begin{array}{l}\text { Fluxo Líquido de } \\
\text { Investimento }\end{array}$} & Pessoa Física & $P F$ & $-0,006$ & 0,070 \\
\hline & Institucional & IN & $-0,013$ & 0,074 \\
\hline & Investior estrangeiro & IE & 0,006 & 0,080 \\
\hline & Empresa & $E P$ & 0,043 & 0,255 \\
\hline & Instituição Financeira & IF & $-0,001$ & 0,108 \\
\hline & Outros & $O U$ & 0,163 & 0,447 \\
\hline \multirow{5}{*}{ Retorno } & Alta elevada & $R^{A E}$ & 0,188 & 0,388 \\
\hline & Alta moderada & $R^{A M}$ & 0,057 & 0,115 \\
\hline & Neutro & $R^{N}$ & 0,000 & 0,014 \\
\hline & Queda moderada & $R^{Q M}$ & 0,054 & 0,115 \\
\hline & Queda elevada & $R^{Q E}$ & 0,194 & 0,446 \\
\hline
\end{tabular}

Nota: A tabela apresenta valores das médias e desvios padrão das variáveis resposta FLI para cada tipo de investidor bem como para as variáveis dependentes. Ambos os grupos de variáveis estão em frequência diária, porém, as variáveis explicativas são calculadas para janelas móveis de cinco dias conforme apresentado na subseção 4.2. O desvio padrão é calculado utilizando Kernel Parzen para considerar o efeito de autocorrelação.

\section{Relações Estimadas}

Esta seção detalha como as regressões do trabalho são realizadas. Primeiro, é explicado como as variáveis dependente e independente são organizadas no tempo. Em seguida é apresentado o modelo estimado e analisado ao longo do estudo.

Para uma melhor compreensão de como a relação entre as variáveis é analisada, deve-se observar a Figura 2. Nota-se que se encontram na figura dois tipos de variáveis independentes: as passadas e as futuras. Variáveis passadas são aquelas calculadas com informações passadas em relação à data de referência da variável dependente; já as variáveis futuras são aquelas calculadas com informações dos dias seguintes à referência em questão. 


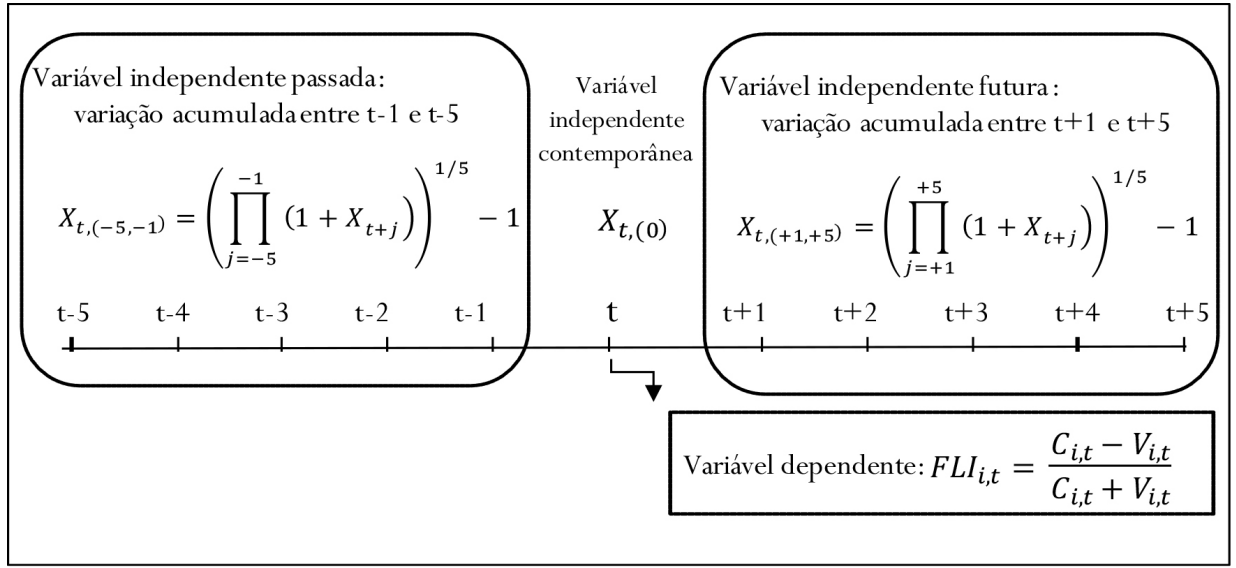

Figura 2 - Disposição das variáveis dependentes e independentes no tempo

Nota: A figura representa como as variáveis das regressões desse estudo são organizadas no tempo. Em que: $X_{t,(-5 ;-1)}$ a a variável independente passada em relação à referência $t ; X_{t,(0)}$ a variável independente contemporânea; $X_{t,(+1 ;+5)}$ a variável independente futura em relação à referência $t ;\left(C_{i, t}-V_{i, t}\right) /\left(C_{i, t}+V_{i, t}\right)$ variável dependente na referência t. Esta representação baseia-se em um exemplo em que a janela é de 5 dias úteis, mas o trabalho desenvolve também análises com 21 e 63 dias úteis.

Finalmente, é possível apresentar o modelo estimado. Para as estimações são feitas regressões para cada tipo de investidores, em que a variável dependente é a variável FLI e as variáveis independentes: (i) retorno acumulado no passado; (ii) o retorno acumulado no futuro. Desta forma chega-se à seguinte relação apresentada na Equação 2:

$$
F L I_{i}=\alpha_{i}+\sum_{j} \beta_{i, j} R_{j}+\varepsilon_{i}
$$

em que:

- $\quad i \in\{P F, I N, I E, I F, E P\}$;

- $j \in\{(-63 ;-22) ;(-21 ;-6) ;(-5 ;-1) ;(0) ;(+1 ;+5) ;(+6 ;+21) ;(+22 ;+63)\}$; sendo os 3 primeiros elementos referentes ao passado e os 3 últimos ao futuro;

- $\alpha_{i}$ é o intercepto do tipo de investidor ;

- $\quad \beta_{i, j}$ é o coeficiente de relação linear entre a variável dependente e o retorno de mercado $R_{j}$; 
- $R_{j}$ é o retorno de mercado calculado de acordo com o disposto na subseção 4.2;

Assim sendo, pela Equação 2, com relação à indicação da adoção de estratégias com base no comportamento passado do indicador de mercado:

- É de se esperar que o sinal de $\beta_{i, j}$ seja positivo e estatisticamente significante se, majoritariamente, o grupo $i$ de investidores aumenta (reduz) as compras líquidas após altas (quedas) do mercado no horizonte $j$. Estaria indicando, portanto, a adoção da estratégia de Momentum.

- É de se esperar que o sinal de $\beta_{i, j}$ seja negativo e estatisticamente significante se, majoritariamente, o grupo $i$ de investidores aumenta (reduz) as compras líquidas após quedas (altas) do mercado no horizonte $j$. Estaria, assim, indicando a adoção de estratégias de Opinião Contrária.

Por sua vez, a análise da relação dos fluxos de investimento com retornos futuros indica a capacidade do grupo em antecipar comportamentos futuros do mercado. Sendo assim:

- É de se esperar que o sinal de $\beta_{i, j}$ seja positivo e estatisticamente significante se, majoritariamente, o grupo $i$ de investidores aumenta (reduz) as compras líquidas antecipadamente às altas (quedas) do mercado no horizonte $j$. Estaria indicando, desta forma, capacidade de antecipar movimentos do mercado.

- É de se esperar que o sinal de $\beta_{i, j}$ seja negativo e estatisticamente significante se, majoritariamente, o grupo $i$ de investidores aumenta (reduz) as compras líquidas antecipadamente às quedas (altas) do mercado no horizonte $j$. Estaria indicando, portanto, histórico com adoção de posições desvantajosas em termos de retorno futuro no horizonte analisado.

Além da relação apresentada na Equação 2 também é feita a estimação da relação representada pela Equação 3, em que as variáveis de retorno de mercado são substituídas por suas cinco variantes detalhadas anteriormente. Com isso obteve-se:

$F L I_{i}=\alpha_{i}+\sum_{j} \beta_{i, P}^{j} R_{\left(-t_{2} ;-t_{1}\right)}^{j}+\beta_{i, 0} R_{(0)}+\sum_{j} \beta_{i, F}^{j} R_{\left(+t_{1} ;+t_{2}\right)}^{j}+\varepsilon_{i}$ 
sendo que:

- $\quad i \in\{P F, I N, I E, I F, E P\}$;

- $j \in\{A E ; A M ; N ; Q M ; Q E\}$;

- $\quad \alpha_{i}$ é o intercepto do tipo de investidor $i$;

- $R_{\left(-t_{2} ;-t_{1}\right)}^{j}$ é o retorno observado no passado no período $(-t 2 ;-t 1)$

- $R_{\left(+t_{1} ;+t_{2}\right)}^{j}$ é o retorno observado no futuro no período $(+t 1 ;+t 2)$;

- $R_{(0)}$ é o retorno de mercado contemporâneo;

- $\quad \beta_{i, P}^{j}$ é o coeficiente de relação linear entre a variável dependente e o retorno de mercado $R_{\left(-t_{2} ;-t_{1}\right)}$;

- $\quad \beta_{i, F}^{j}$ é o coeficiente de relação linear entre a variável dependente e o retorno de mercado $R_{\left(+t_{1} ;+t_{2}\right)}^{j}$;

- $\beta_{i, 0}$ é o coeficiente da relação linear entre a variável dependente e o retorno de mercado contemporâneo $R_{(0)}$.

Essa equação permite que seja testada a ocorrência de comportamentos assimétricos por parte de algum grupo de investidor, tais como Efeitos Disposição e Stop Loss.

Para tanto, os coeficientes devem apresentar os seguintes comportamentos:

- No caso da hipótese de Efeito Disposição, coeficientes $\beta_{i, P}^{A E}$ e $\beta_{i, P}^{A M}$ negativos e estatisticamente diferentes de zero, por outro lado, os coeficientes $\beta_{i, P}^{Q E}$ e $\beta_{i, P}^{Q M}$ tendem a ser maiores que coeficientes anteriores (iguais a zero ou positivos), porém menores em módulo. Esse padrão indica assimetria na relação do investidor a ganhos e perdas. Imaginando que a maior parte dos investidores adote posições compradas, essa combinação indica que o grupo $i$ de investidores atua com mais intensidade nas altas da bolsa, reduzindo posição que nas baixas, comprando posição.

- No caso da hipótese de adoção de Stop Loss, considerando que o tipo de posição padrão entre os investidores é uma posição comprada em ações, coeficientes $\beta_{i, P}^{Q E}$ e $\beta_{i, P}^{Q M}$ tendem a ser negativos e estatisticamente diferentes de zero. Comportamento esse aderente com estratégias de Stop-Loss como mecanismo de liquidação de posições. 
Portanto, chega-se a dois tipos de regressões muito semelhantes entre si. Ambas procuram captar como os comportamentos de alguns tipos de investidores se relacionam com as variações da bolsa. O segundo tipo de regressão é semelhante ao primeiro, à medida que procura distinguir a relação do comportamento dos investidores com relação às quedas do mercado e às elevações do mercado. Objetiva-se com esse segundo modelo, determinar a existência de assimetrias de comportamento de cada grupo de investidores com relação aos movimentos de alta e de baixa nos preços em geral das ações.

\section{Resultados}

\subsection{Retorno de Mercado Passado Influenciando as Decisões Presentes}

Investiga-se, em primeiro lugar, a correlação existente entre os fluxos de investimento, sintetizados pela variável FLI, com os retornos médios construídos para os intervalos do passado, presente e futuro. Especificamente são calculados os coeficientes de correlação entre os fluxos de investimento FLI e as variáveis, anteriormente apresentadas na seção 3.3. Nesse primeiro momento não são analisadas significâncias estatísticas das relações estimadas. Essas análises são feitas mais adiante.

O resultado obtido é resumido na Figura 3 a seguir. A figura retrata o coeficiente de correlação entre retornos passados, contemporâneos e futuros em relação a variável FLI. Cada gráfico na figura destaca um grupo de investidores. No eixo vertical é informado o valor da correlação. No eixo horizontal é informado a janela de retorno analisada. 


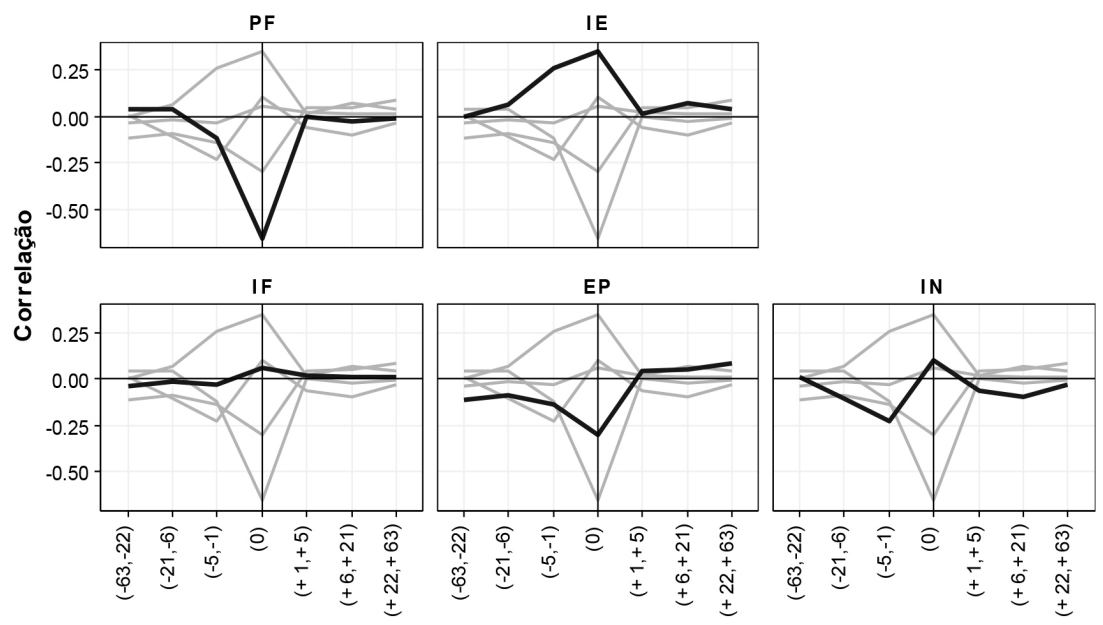

Figura 3 - Correlação do Fluxo de Investimento e Retorno de Mercado $R\left(t_{1} ; t_{2}\right)$

Nota: A figura apresenta a correlação entre Fluxo de Investimento e Retorno de Mercado para diferentes horizontes e grupos de investidores. A sigla PF refere-se ao grupo pessoa física, IE aos investidores estrangeiros, IF às instituições financeiras, EP às empresas, e IN ao grupo de investidores institucionais.

Como pode ser observado, existem padrões bastante distintos entre os diferentes grupos de investidores, ainda que para quase todos percebe-se um domínio dos efeitos contemporâneos na relação com fluxo de investimentos, com nítida diminuição da influência à medida em que se afasta no tempo para defasagens e avanços mais remotos.

O grupo de investidores estrangeiros (IE) apresenta um dos comportamentos mais destoantes em relação aos demais. Para esse grupo o padrão observado com retornos passados é condizente com o esperado por um investidor que siga estratégias de investimento de Momentum, uma vez que a relação entre $F L I$ e retornos é positiva. Além disso, a correlação futura positiva indica que esse grupo tenha acesso a melhores informações ou que possua uma melhor capacidade de processamento dessas informações.

Embora os valores dos coeficientes de correlação com os retornos futuros de mercado sejam muito inferiores àqueles observados para retornos passados, a mesma dominância é encontrada para todos os demais grupos de investidores quando se compara as correlações com os retornos passados e com os futuros. O grupo IE é, inclusive, o único tipo de investidor a apresentar correlação positiva com retornos passados entre 1 e 5 dias. 
Observa-se que o investidor do tipo PF responde negativamente a retornos passados na janela que abrange os últimos 5 dias de negociação, comportamento esse condizente com o de opinião contrária. Contudo, esse comportamento é também condizente com o Efeito Disposição, uma vez que sua correlação negativa com retornos passados pode ser devido à tendência a realizar movimentos de venda após movimentações passadas positivas nos preços. Note também que o fluxo de investimentos do grupo PF apresenta correlação positiva com retornos passados para janelas defasadas de horizontes mais distantes, o que pode indicar que o grupo define suas expectativas baseando-se em informações de longo prazo.

O grupo empresas (EP) ao contrário do grupo IE apresenta correlação negativa para todos os horizontes passados e para o contemporâneo. Por outro lado, a correlação do seu fluxo de investimentos com retornos futuros se mostra positiva para todos os três horizontes analisados e é a mais alta, entre todos os grupos, para o maior horizonte analisado, 22 a 63 dias úteis.

Os investidores institucionais (IN) apresentam correlação negativa com retornos de todos horizontes exceto o contemporâneo, indicativo também de comportamento motivado por Opinião Contrária. O valor absoluto das correlações com retornos passados se eleva quanto mais próximo é o horizonte analisado, e a correlação negativa com retornos futuros são as maiores, em valores absolutos, dentre as correlações com retornos futuros.

Por fim, tem-se as correlações para o grupo de instituições financeiras (IF). O fluxo de investimentos desse grupo não indica correlação com retornos passados, contemporâneos ou futuros. Nesse sentido o comportamento desse grupo é o que mais se enquadra no padrão esperado pela teoria clássica, segundo a qual não deve existir relação entre retornos passados ou futuros e os fluxos de investimentos.

Diante desses resultados iniciais, busca-se mensurar a significância dessas relações ao estimar o modelo dado pela Equação 2 e descrito na seção 4 . Com a estimação da regressão se pode separar o efeito dos retornos de cada janela sobre o fluxo de investimentos. Os resultados são apresentados na Tabela 3. Na parte superior da tabela, há a descrição de cada grupo de investidores, sendo que na primeira coluna estão apresentadas as variáveis explicativas de retorno. 
Os resultados apresentados na Tabela 3 confirmam a análise feita anteriormente com base na Figura 3. O grupo de investidores PF apresenta relação positiva e significante com retornos passados de horizontes mais longos, indicativo da estratégia Momentum. Por outro lado, as relações se mostram negativas para os horizontes passados mais curtos, típico de Opinião Contrária.

O grupo de investidores IE para os horizontes de até 21 dias apresenta relação positiva e significante. Essa evidência permite classificar os investidores não residentes como adeptos, majoritariamente, da estratégia Momentum. Além disso, os coeficientes associados ao retorno futuro são positivos e significantes até 21 dias úteis, indicando que esse grupo de investidores acelera as compras líquidas antes da bolsa subir e aumenta as vendas líquidas dias antes da bolsa cair.

O investidor do grupo IF não demonstra significância para nenhum horizonte exceto o contemporâneo, mostrando que esse tipo de investidor não é influenciado pelo retorno passado, tampouco pelo retorno futuro. Assim, seu processo decisório poderia ser, em princípio, compatível com o investidor típico preconizado pela teoria econômica.

Os resultados encontrados apontam significância negativa na relação do fluxo de investimentos dos investidores EP com retornos passados em todos horizontes. Em relação a retornos futuros observa-se significância positiva nos horizontes de médio e longo prazo. O primeiro efeito é compatível com comportamento de Opinião Contrária e o segundo efeito indica capacidade desse grupo de investidores em antecipar movimentos de alta e baixa de mercado com certa regularidade.

Por fim, o grupo de IN apresenta o resultado mais paradoxal dentre todos os demais analisados, uma vez que apresenta relação negativa tanto com os retornos passados como com os futuros. Esse resultado sugere que os investidores IN elevam seus fluxos de investimentos anteriormente às quedas futuras do mercado, ou seja, o resultado sugere que o investidor em questão sofre perdas sistemáticas no período analisado. 
Tabela 3 - Regressões Fluxo Líquido de Investimento contra retornos de mercado

\begin{tabular}{llllll}
\hline & PF & IE & IF & EP & IN \\
\hline $\mathrm{R}_{(-63,-22)}$ & $0,014^{* *}$ & $-0,004$ & $-0,018$ & $-0,127^{* * *}$ & 0,008 \\
$\mathrm{R}_{(-21,-6)}$ & 0,008 & $0,015^{* * *}$ & $-0,005$ & $-0,073^{* * *}$ & $-0,022^{* * *}$ \\
$\mathrm{R}_{(-5,-1)}$ & $-0,017^{* * *}$ & $0,033^{* * *}$ & $-0,005$ & $-0,062^{* * *}$ & $-0,025^{* * *}$ \\
\hline $\mathrm{R}_{(0)}$ & $-0,029^{* * *}$ & $0,018^{* * *}$ & $0,004^{* *}$ & $-0,049 * * *$ & $0,004^{* * *}$ \\
\hline $\mathrm{R}_{(+1,+5)}$ & $-0,006^{* * *}$ & $0,007^{* * *}$ & 0,003 & 0,007 & $-0,008^{* * *}$ \\
$\mathrm{R}_{(+6,+21)}$ & $-0,005$ & $0,012^{* *}$ & 0,005 & $0,049 * *$ & $-0,019^{* * *}$ \\
$\mathrm{R}_{(+22,+63)}$ & 0,001 & 0,007 & 0,006 & $0,108^{* * *}$ & $-0,003$ \\
Constante & $-0,006^{* * *}$ & $0,005^{* *}$ & $-0,002$ & $0,041^{* * *}$ & $-0,011^{* * *}$ \\
\hline Obs. & 2.503 & 2.503 & 2.503 & 2.503 & 2.503 \\
$\mathrm{R}^{2}$ & 0,466 & 0,212 & 0,007 & 0,150 & 0,088 \\
$\mathrm{R}^{2}$ ajustado & 0,464 & 0,210 & 0,004 & 0,148 & 0,085 \\
teste-F & $310,759^{* * *}$ & $95,746^{* * *}$ & $2,388^{* *}$ & $63,145^{* * *}$ & $34,364 * * *$ \\
\hline & & & & & \\
\hline
\end{tabular}

Nota: As colunas na tabela apresentam o resultado da regressão utilizando a variável dependente $F L I$ para cada tipo de investidor e as variáveis independentes, destacadas na primeira coluna. Para tratar o efeito da autocorrelação é aplicado Kernel Parzen no cálculo da significância das variáveis, onde ${ }^{* * *},{ }^{* *} \mathrm{e}^{*}$ representam estatisticamente significativo nos níveis de $1 \%, 5 \%$ e $10 \%$, respectivamente.

As análises acima sinalizam algumas características interessantes sobre os comportamentos dos grupos de investidores analisados. O grupo PF é potencialmente influenciado pelo Efeito Disposição no curto prazo, contudo, em relação aos retornos de longo prazo, indica seguir a estratégia de Momentum. O IE aparenta seguir estratégias de Momentum e seus fluxos de investimento parecem antecipar retornos futuros. O grupo IF não é afetado por retornos passados ou relacionado com retornos futuros. $\mathrm{O}$ segmento EP antecipa retornos futuros do mercado e é fortemente negativo correlacionado com retornos passados. Por fim, o investidor do tipo IN apresenta fluxo de investimento relacionados negativamente com retornos futuros. 


\subsection{Assimetria na Reação dos Investidores}

Diante das evidências destacadas na subseção 5.1, o próximo passo é analisar a assimetria nas relações entre FLI e retorno passados e futuros. O intuito desta investigação é verificar se movimentações mais voláteis produzem efeito distinto de movimentações menos voláteis. Além disso, essa seção possibilitou diferenciar o efeito de retornos positivos e negativos sobre o FLI de cada grupo de investidores.

Para realizar essa análise a variável explicativa retorno de mercado é tratada conforme apresentado na subseção 3.3. A Tabela 4 reúne os resultados das regressões estimadas a partir das variáveis independentes, construídas com horizontes de tempo de cinco dias úteis. A primeira coluna indica as variáveis utilizadas, conforme abreviações encontradas na subseção 3.3. As cinco colunas subsequentes revelam os resultados para a Equação 3, em que a variável de retorno de mercado é subdividida por faixa de intensidade e direção.

Os resultados alcançados revelam evidências do que pode ser atribuído ao Efeito Disposição, discorrido na seção 2, em relação ao comportamento agregado dos investidores PF. Quando se pondera o resultado de reações assimétricas apresentado na Tabela 4 para estes investidores, tal hipótese ganha mais força. Aqui se constata a significância de $1 \%$ das variáveis de retorno passado para Alta Elevada (AE) e Alta Moderada (AM), ambas apresentando também coeficientes negativos. Enquanto que para retornos passados negativos, Quedas Moderadas (QM) apresentam significância apenas ao nível de $10 \%$.

Conclui-se, por conseguinte, que a resposta desse tipo de investidor é mais forte ante os ganhos do que as perdas, o que evidencia que após ganhos, o mesmo está mais inclinado a realizar seus lucros, porém sua reação é mais fraca quando se trata de perdas, as quais presumivelmente são realizadas com menor intensidade.

Similar reação é verificada para os tipos EP e IN, com algumas ressalvas. Ambos os grupos de investidores exibem sinais negativos e significantes nos resultados para as variáveis de retorno passado de mercado. Não apresentam, todavia, a assimetria nos resultados da Tabela 4, como observado para o grupo PF. 
Tabela 4 - Comportamento dos investidores (janelas de 5 dias úteis)

\begin{tabular}{|c|c|c|c|c|c|}
\hline & PF & IE & IF & EP & IN \\
\hline $\mathrm{R}_{(-5,-1)}^{\mathrm{AE}}$ & $-0,01^{* * *}$ & $0,03^{* * *}$ & 0,00 & $-0,03$ & $-0,02^{* * *}$ \\
\hline $\mathrm{R}_{(-5,-1)}^{\mathrm{AM}}$ & $-0,03^{* * *}$ & $0,08^{* * *}$ & 0,00 & $-0,15^{* * *}$ & $-0,04^{* * *}$ \\
\hline$R_{(-5,-1)}^{N}$ & $-0,06$ & $-0,05$ & 0,09 & 0,02 & 0,09 \\
\hline$R_{(-5,-1)}^{Q M}$ & $0,02^{*}$ & $-0,03^{*}$ & $-0,02$ & 0,05 & $0,03^{* *}$ \\
\hline $\mathrm{R}_{(-5,-1)}^{\mathrm{QE}}$ & $0,02^{* * *}$ & $-0,03^{* * *}$ & 0,01 & $0,08^{* * *}$ & $0,03^{* * *}$ \\
\hline$R_{(0)}$ & $-0,03^{* * *}$ & $0,02^{* * *}$ & $0,004^{* *}$ & $-0,05^{* * *}$ & $0,003^{* * *}$ \\
\hline $\mathrm{R}^{\mathrm{AE}}{ }_{(+1,+5)}$ & 0,00 & 0,00 & 0,01 & $0,03^{*}$ & $-0,01^{*}$ \\
\hline $\mathrm{R}_{(+1,+5)}^{\mathrm{AM}}$ & 0,00 & $-0,01$ & 0,03 & 0,01 & 0,00 \\
\hline $\mathrm{R}_{(+1,+5)}^{\mathrm{N}}$ & $-0,02$ & 0,11 & $-0,01$ & $-0,09$ & $-0,11$ \\
\hline $\mathrm{R}_{(+1,+5)}^{\mathrm{QM}}$ & 0,01 & $-0,02$ & $-0,02$ & 0,01 & 0,01 \\
\hline$R^{Q E}{ }_{(+1,+5)}$ & $0,01^{* * *}$ & $-0,01^{* * *}$ & 0,00 & $0,03^{* *}$ & $0,01^{* *}$ \\
\hline Constante & $-0,01^{* * *}$ & $0,01^{*}$ & 0,00 & $0,03^{*}$ & $-0,01 * * *$ \\
\hline Obs. & 2.619 & 2.619 & 2.619 & 2.619 & 2.619 \\
\hline $\mathrm{R}^{2}$ ajustado & 0,46 & 0,21 & 0,00 & 0,13 & 0,07 \\
\hline
\end{tabular}

Nota: As colunas na tabela apresentam o resultado da regressão utilizando a variável dependente FLI para cada tipo de investidor e as variáveis independentes, denotadas na primeira coluna, estimadas com intervalos de 5 dias. Para lidar com efeito da autocorrelação é aplicado Kernel Parzen no cálculo da significância das variáveis, onde ${ }^{* * *},{ }^{* *} \mathrm{e}{ }^{*}$ representam estatisticamente significativo nos níveis de $1 \%, 5 \%$ e $10 \%$, respectivamente.

Deve ser destacada a significância de retornos futuros observada para IN, que aponta para relação negativa entre movimentos de compra e retornos futuros, especialmente no tocante a quedas e altas elevadas. Tal efeito surpreende, pois não é habitual se chegar a resultados estatisticamente significantes negativos ou positivos. No caso dos coeficientes positivos, no entanto, a anormalidade pode ser justificada pela presença de um melhor acesso à informação e processamento superior das informações públicas, com o objetivo de se obter maiores rendimentos. Por outro lado, não se chega à mesma conclusão no caso de resultados significantes e negativos.

Com base nos resultados da Tabela 3, nota-se que o grupo IE exibe comportamento diferente dos demais, sendo o único a apresentar sinal positivo para retornos passados e também futuros. Parte da atuação desse grupo de investidores apresenta relação positiva e significante com retornos futuros 
de mercado, revelando possuir certa capacidade de previsão dos movimentos futuros de mercado.

Ademais, o exame dos resultados da Tabela 4 para o tipo de investidor IE permite ainda destacar que a significância ocorre apenas para Quedas Elevadas (QE). Tal fato sugere que esse grupo de investidores dispõe de uma habilidade de previsão de retornos futuros ligadas a grandes quedas futuras nos preços dos ativos.

As principais observações realizadas para a janela de 5 dias úteis encontram-se resumidas no Quadro 1 seguinte.

Quadro 1 - Comportamento Padrão por Tipo de Investidor

\begin{tabular}{cccc}
\hline \multirow{2}{*}{ Investidor } & \multicolumn{2}{c}{ Passado } & \multirow{2}{*}{ Futuro } \\
\cline { 2 - 3 } & Curto prazo & Médio / Longo prazo & \\
\hline PF & $\begin{array}{c}\text { Opinião contrária potencial- } \\
\text { mente afetado por Efeito } \\
\text { Disposição }\end{array}$ & Momentum & Relação negativa \\
IE & Momentum & Momentum & Relação positiva \\
IF & Sem relação & Sem relação & Sem relação \\
EP & Opinião contrária & Opinião contrária & Relação positiva \\
IN & Opinião contrária & Opinião contrária & Relação negativa \\
\hline
\end{tabular}

\section{Conclusão}

O trabalho tem como objetivo investigar a relação do fluxo de investimentos de determinados tipos de investidores com retornos passados e futuros do mercado de ações brasileiro.

Tome-se um grupo de investidores, por exemplo as pessoas físicas. Elas não tomam decisões de forma coordenada, não possuem acesso ao mesmo conjunto de informações e não dispõem da mesma capacidade de processamento e análise das informações disponíveis. Assim, descobrir que um grupo de investidores possui, de forma majoritária e em média, uma mesma estratégia de investimento ou, contrariando o que é determinado pela teoria econômica, que seus componentes reagem de uma mesma forma às mudanças de mercado, é algo de interesse e relevância. 
A bibliografia concernente demonstra, para diferentes economias no mundo, que os investidores tomam suas decisões de investimento baseando-se tanto em comportamentos passados como nas suas expectativas de comportamento futuro do mercado, muito embora esta relação seja menos evidente no segundo caso. A respectiva literatura também constata que essas relações se distinguem conforme o grupo de investidores analisado. Este estudo apura que as mesmas conclusões são válidas para o mercado brasileiro e têm impacto no comportamento agregado dos grupos de investidores.

Observa-se que todos os grupos de investidores examinados, à exceção de Instituições Financeiras (IF), estão sujeitos à influência de movimentos passados do mercado. O grupo Investidores estrangeiros (IE) constitui-se o único a apresentar relação positiva entre o retorno passado e o seu volume líquido de compras, sinalizando um perfil estratégico de feedback positivo ou Momentum. Todos os outros grupos, em que se verifica significância na relação com retornos passados, exibem o perfil estratégico de feedback negativo, uma estratégia do tipo Opinião Contrária.

A partir dos resultados alcançados, concluiu-se que o mercado brasileiro é formado por diferentes tipos de investidores, com perfis de investimento distintos e passíveis de tipificação. Investidores estrangeiros (IE) são os únicos a apresentar comportamento de feedback positivo e significante. Os resultados para PF evidenciam que tal grupo possui um perfil de negociação mais isolado dos demais e mais suscetível a tomadas de decisão psicológicas. 


\section{Referências}

Abinzano, I.; Muga, L.; Santamaria, R. 2010. The role of over-reaction and the disposition effect in explaining momentum in Latin American emerging markets. Investigación Económica, p. 151-186.

Badrinath, S. G.; Wahal, S. 2002. Momentum Trading by Institutions. Journal of Finance 57(6): 2449-2478.

Bondt, W. F. M. De; Thaler, R. 1985. Does the Stock Market Overreact? The Journal of Finance 40(3): 793-805, jul.

Chan, K. C. 1988. On the Contrarian Investment Strategy. The Journal of Business 61(2): 147, jan.

Costa Jr., N. et al. 2008. Disposition effect and gender. Applied Economics Letters 15(6): 411-416.

Costa Jr, N.; Goulart, M.; Cupertino, C.; Macedo Jr., J.; et al. 2013. The disposition effect and investor experience. Journal of Banking \& Finance 37(5): 1669-1675.

Coval, J. D.; Shumway, T. 2005. Do behavioral biases affect prices? Journal of Finance 60(1): 1-34.

Cutler, D. M.; Poterba, J. M.; Summers, L. H. 1991. Speculative Dynamics. The Review of Economic Studies 58(3): 529, maio.

Edelen, R. M.; Marcus, A. J.; Tehranian, H. 2010. Relative sentiment and stock returns. Financial Analysts Journal 66(4): 20-32.

Fama, E. F.; French, K. R. 1988. Permanent and Temporary Components of Stock Prices. Journal of Political Economy 96(2): 246-273, abr.

Froot, K. A.; O’connell, P. G. J.; Seasholes, M. S. 2001. The portfolio flows of international investors. Journal of Financial Economics 59(2): 151-193.

Griffin, J. M.; Harris, J. H.; Topaloglu, S. 2003. The dynamics of institutional and individual trading. Journal of Finance 58(6): 2285-2320.

Grinblatt, M.; Keloharju, M. 2000. The investment behavior and performance of various investor types : a study of Finland 's unique data set. Journal of Financial Economics 55(1): 43-67.

Grinblatt, M.; Titman, S.; Wermers, R. 1995. Momentum investment strategies, portfolio performance, and herding: A study of mutual fund behavior. The American Economic Review, 1088-1105.

Guercio, D. Del; Tkac, P. A. 2002. The determinants of the flow of funds of managed portfolios: Mutual funds vs. pension funds. Journal of Financial and Quantitative Analysis 37(04): 523-557.

Jegadeesh, N.; Titman, S. 1993. Returns to Buying Winners and Selling Losers: Implications for Stock Market Efficiency. Journal of Finance 48(1): 65.

Kahneman, D.; Tversky, A. 1979. Prospect theory: An analysis of decision under risk. Econometrica: Journal of the Econometric Society, p. 263-291.

Kamesaka, A.; Nofsinger, J. R.; Kawakita, H. 2003. Investment patterns and performance of investor groups in Japan. Pacific Basin Finance Journal 11(1): 1-22.

Karsten, J. G. 2005. O efeito de disposição: um estudo empírico no Brasil. [s.1.] Dissertação Escola de Economia de São Paulo Getúlio Vargas.

Lakonishok, J.; Shleifer, A; Vishny, R. 1992. The Structure and Performance of the Money Management Industry. Brookings Papers on Economic Activity 1992, n. 1992, p. Brookings Pap. Econ. Act.

Lakonishok, J.; Shleifer, A.; Vishny, R. 1992. The Impact of Institutional Trading on Stock Prices. Journal of Financial Economics 32(1).

Lee, J.-S.; Shen, C.-H.; Yen, P.-H. 2010. The study of the fund investors' disposition effect vis-à-vis herding redemption and non-herding redemption: evidence from quantile regression least square dummy variable estimator. Journal of Management and System 17(1): 1331-1342.

Lee, J.-S.; Yen, P.-H.; Chan, K. C. 2013. Market states and disposition effect: evidence from Taiwan mutual fund investors. Applied Economics 45(10): 1331-1342. 
Lucchesi, E. P.; Yoshinaga, C. E.; Castro Jr., F. H. F. 2015. Disposition effect among Brazilian equity fund managers. Revista de Administração de Empresas 55(1): 26-37.

Muga, L.; Santamaria, R. 2007. The momentum effect in Latin American emerging markets. Emerging Markets Finance and Trade 43(4): 24-45.

O'Connell, P. G. J.; Teo, M. 2009. Institutional investors, past performance, and dynamic loss aversion. Journal of Financial and Quantitative Analysis 44(01): 155-188.

Odean, T. 1998. Are investors reluctant to realize their losses? Journal of finance 53(5): 1775-1798.

Osler, C. L. 2003. Currency Orders and Exchange Rate Dynamics: An Explanation for the Predictive Success of Technical Analysis. Journal of Finance 58(5): 1791-1819.

Poterba, J. M.; Summers, L. H. 1988. Mean reversion in stock prices: Evidence and Implications. Journal of Financial Economics 22(1): 27-59.

Shefrin, H.; Statman, M. 1985. The disposition to sell winners too early and ride losers too long: Theory and evidence. Journal of Finance, p. 777-790. 